\title{
VZTAH MEZI PŘIROZENOU RADIOAKTIVITOU HORNIN A PŮD NA NICH VYTVOŘENÝCH - ZÁKLADNÍ PROBLÉM INTERPRETACE DAT ZÍSKANÝCH LETECKOU A TERÉNNII GAMASPEKTROMETRIÍ
}

\author{
The relationship between the natural radioactivity of rocks and soils formed on them - the \\ basic problem of the interpretation of data gathered by airborne and field gamma-ray \\ spectrometry
}

\author{
Jiří Zimák \\ Katedra geologie PřF UP, tř. 17. listopadu 12, 771 46 Olomouc; e-mail: zimak@prfnw.upol.cz
}

(14-12 Deštné, 14-22 Jeseník, 14-24 Bělá pod Pradědem, 14-41 Šumperk, 14-42 Rýmařov, 14-43 Mohelnice, 14-44 Šternberk, 15-13 Vrbno pod Pradědem, 15-33 Moravský Beroun, 23-42 Třebíč, 24-21 Jevíčko, 24-23 Protivanov, 24-33 Moravský Krumlov, 24-41 Vyškov)

Key words: soils, rocks, gamma-spectrometry, natural radioactivity, gamma dose rate

\begin{abstract}
The objective of this study was to assess the amount of natural radionuclides in fresh parent rocks and their effect on natural radioactivity of soils developed from them. Forty-five fresh rocks consisting mainly of granitoids, syenitoids, acid to basic metavolcanites, mica schists, gneisses, quartzites, serpentinites, sandstones, graywackes, and limestones and their corresponding overlying soils were sampled for laboratory gamma-ray spectrometric analysis. Contents of potassium, uranium and thorium were converted to mass activity of ${ }^{226} \mathrm{Ra}$ equivalent $\left(a_{m}\right)$ and terrestrial gamma radiation dose rate $(D)$. Data are tabled and discussed.

The highest $a_{m}$ values occured in syenitoids (386-441 Bq. $\left.\mathrm{kg}^{-1}\right)$ followed by granitoids, mica schists, greywackes and gneisses, whereas the lowest $a_{m}$ values were found in quartzose sandstones (15-36 Bq. $\mathrm{kg}^{-1}$ ) followed by limestones (less than $15 \mathrm{~Bq} \cdot \mathrm{kg}^{-1}$ ) and serpentinites (less than $6 \mathrm{~Bq} \cdot \mathrm{kg}^{-1}$ ). The natural radioactivity of soils is usually slightly lower than that of parent rocks due to the lower content of potassium, uranium and thorium in soils. This is typical for granitoids, syenitoids and rocks of similar mineralogical composition. In soils developed on granitoids and syenitoids were found increased concentrations of all three elements in the grain size fraction below $0.063 \mathrm{~mm}$. Soils developed on rocks with low natural radioactivity (such as limestones and serpentinites) tend to have significantly higher natural radioactivity than their parent rocks. This may complicate the interpretation of data obtained by airborne gamma-ray spectrometry.
\end{abstract}

Úvod

Při interpretaci dat získaných leteckou nebo terénní gamaspektrometrií může být zásadním problémem vztah mezi obsahem přirozených radioaktivních prvků v hornině $\mathrm{a} v$ půdě na ní vytvořené. $V$ literatuře lze často najít formulace typu „obecně platí, že půdy a zvětralé vrstvy mají obsahy $\mathrm{K}, \mathrm{U}$, Th menší než nerozrušená podložní hornina“" (např. Matolín - Chlupáčová 1997). Výsledky předložené práce umožňují posoudit, do jaké míry jsou taková tvrzení oprávněná.

\section{Vzorky a metody}

Vzorky hornin a půd byly odebrány na 45 lokalitách (I až XLV) ve v. části Českého masivu. Nejzákladnější údaje o těchto lokalitách poskytuje přehled $\mathrm{v}$ tabulce 1 .

Všechny lokality jsou na elevacích, na nichž vždy vystupuje pouze jeden horninový typ, půdy nejsou ovlivněny zemědělskou činností a genetické sepětí půdy s horninou je zde víceméně jisté. $V$ prostoru každé lokality byly odebrány nejméně tři vzorky hornin a nejméně tř̌i půdní vzorky (celkem jde o 514 vzorků).

Vzorky půd byly odebírány $\mathrm{z}$ hloubky zhruba 15 až $20 \mathrm{~cm}$ pod povrchem (šlo o luvisoly a leptosoly, horizonty $A$ až $C$, dominantně $B$ ), př́padné větší fragmenty hornin byly odstraněny. Po vysušení byly z půdních vzorků pomocí stavebního síta odděleny úlomky hornin a také fragmenty rostlin o velikosti cca nad $5 \mathrm{~mm}$. Po stanovení obsahu $\mathrm{K}$,
U a Th v takto připravených půdních vzorcích (viz níže) byly vzorky půd z téže lokality spojeny do vzorku jediného. Z tohoto vzorku byly sítováním za sucha za použití sady sít $s$ velikostí oka $2 \mathrm{~mm}, 0,5 \mathrm{~mm}$ a $0,063 \mathrm{~mm}$ připraveny čtyři zrnitostní frakce. Frakce pod $0,063 \mathrm{~mm}$ byla prrímo použita ke stanovení obsahu K, U a Th. Frakce 0,063 až $0,5 \mathrm{~mm}$ a 0,5 až $2 \mathrm{~mm}$ byly na sítech propláchnuty vodou, a tak z nich byly odstraněny jak menši částice, ale v podstatné míre i zbytky suché rostlinné hmoty. Obě frakce byly následně vysušeny a použity ke stanovení obsahu $\mathrm{K}, \mathrm{U}$ a Th. Frakce nad $2 \mathrm{~mm}$ dále využita nebyla, i když její př́tomnost může i zásadně ovlivnit celkový obsah sledovaných prvků v půdě (obsah K, U a Th ve frakci nad $2 \mathrm{~mm}$ víceméně odpovídá obsahu těchto prvků v matečné hornině). Uvedeným způsobem byly zpracovány půdní vzorky z 20 lokalit.

V horninových a půdních vzorcích byly na PřF UP v Olomouci za použití spektrometru SG - 1000 LAB s $\mathrm{NaI}(\mathrm{Tl})$ detektorem o objemu $0,35 \mathrm{dm}^{3}$ (průměr $76 \mathrm{~mm}$, délka $76 \mathrm{~mm}$ ) stanoveny obsahy draslíku, uranu a thoria. Před měrením byly horninové vzorky rozdrceny a uzavřeny do krabiček o objemu $250 \mathrm{ml}$, v nichž byly následně měřeny. Hmotnost takto prípravených vzorků se pohybovala kolem 400 gramů. Stejné krabičky byly použity i pro půdní vzorky.

Přirozená radioaktivita hornin a půd je hodnocena na základě hmotnostní aktivity ekvivalentu ${ }^{226} \mathrm{Ra}\left(\mathrm{a}_{\mathrm{m}}\right)$ a též dávkového př́konu záření gama terestrického půvo- 
Tab. 1: Přehled odebraných vzorků.

Tab. 1: List of samples.

\begin{tabular}{|c|c|c|c|}
\hline lokalita & typ horniny & geol. jednotka & katastrální území \\
\hline $\mathrm{I}$ & ortorula & keprnická sk. & Bukovice u Velkých Losin \\
\hline II & ortorula & keprnická sk. & Pekařov \\
\hline III & metaprachovec & zábřežská sk. & Krchleby na Moravě \\
\hline IV & metadroba & zábřežská sk. & Lupěné \\
\hline $\mathrm{V}$ & amfibolit & zábřežská sk. & Hynčina \\
\hline VI & fylonit & desenská sk. & Kouty nad Desnou \\
\hline VII & fylit & vrbenská sk. & Domašov u Jeseníka \\
\hline VIII & svor & vrbenská sk. & Kouty nad Desnou \\
\hline IX & svor & sk. Branné & Kouty nad Desnou \\
\hline $\mathrm{X}$ & ortorula & sněžnicko-gierałtówská sk. & Velký Uhřínov \\
\hline XI & ortorula & sněžnicko-gierałtówská sk. & $\begin{array}{l}\text { Kunštát u Orlického Záhoři } \\
\text { a Malá Zdobnice }\end{array}$ \\
\hline XII & svor & mlynowiecko-stroňská sk. & Sedloňov \\
\hline XIII & metakeratofyr & vrbenská sk. & Oskava \\
\hline XIV & světlý metatuf & vrbenská sk. & Horní Město \\
\hline $\mathrm{XV}$ & bazický metatuf & vrbenská sk. & Plinkout \\
\hline XVI & kvarcit & staroměstská sk. & Petř́kov \\
\hline XVII & mylonitizovaná ortorula & keprnická sk. & Adolfovice \\
\hline XVIII & amfibolit & vrbenská sk. & Adolfovice \\
\hline XIX & metaprachovec & sk. Videlského potoka & Domašov u Jeseníku \\
\hline $\mathrm{XX}$ & granit & žulovský pluton & Kobylá nad Vidnavkou \\
\hline XXI & granit & žulovský pluton & Stará Červená Voda \\
\hline XXII & kvarcit & vrbenská sk. & Rejvíz \\
\hline XXIII & droba & hornobenešovské s. & Dalov \\
\hline XXIV & paleobazalt & stínavsko-chabičovské s. & Chabičov \\
\hline XXV a XXVI & vápnitý pískovec & jizerské s. & Gruna \\
\hline XXVII & vápnitý pískovec & jizerské s. & Bohdalov \\
\hline XXVIII & vápenec & macošské s. & Březina \\
\hline XXIX a XXX & granit až křemenný syenit & třebíčský masiv & Pocoucov \\
\hline XXXI & granit až křemenný syenit & třebíčský masiv & Ptáčov \\
\hline XXXII & granit až křemenný syenit & třebíčský masiv & Kožichovice \\
\hline XXXIII & droba & protivanovské s. & Obectov \\
\hline XXXIV & droba & protivanovské s. & Loštice \\
\hline XXXV & droba & hornobenešovské s. & Komora a Hejnov \\
\hline XXXVI & migmatit & př́íkrov Keprníku & Adolfovice \\
\hline XXXVII & serpentinit & ve staroměstských pásmech & Raškov-Ves \\
\hline XXXVIII & granit & žulovský pluton & Žulová \\
\hline XXXIX & droba & andělskohorské s. & Dlouhá Voda \\
\hline $\mathrm{XL}$ & paleobazalt & stínavsko-chabičovské s. & Moravský Beroun \\
\hline XLI & vápenec & macošské s. & Lipovec \\
\hline XLII a XLIII & vápenec & macošské s. & Suchdol \\
\hline XLIV a XLV & serpentinit & gföhlská jednotka & Mohelno \\
\hline
\end{tabular}

du (D). Z výsledků gamaspektrometrických analýz byly tyto parametry vypočteny pomocí vztahů $\mathrm{a}_{\mathrm{m}}=(0,077 \times$ $313 \mathrm{~K})+12,35 \mathrm{U}+(1,43 \times 4,06 \mathrm{Th}), \mathrm{D}=(0,043 \times 313 \mathrm{~K})+$ $(0,427 \times 12,35 \mathrm{U})+(0,662 \times 4,06 \mathrm{Th})$, do nichž je obsah K dosazován v hm. \%, obsahy U a Th v ppm (UNSCEAR 1988; Matolín - Chlupáčová 1997; Ngachin et al. 2007).

\section{Výsledky a diskuze}

$\mathrm{V}$ tabulce 2 jsou sumarizovány výsledky všech gamaspektrometrických stanovení $\mathrm{K}, \mathrm{U}$ a Th ve vzorcích matečných hornin (sloupce s označením „h“) a ve vzorcích půd, které se na těchto horninách vytvořily („p“), a též vypočtené hodnoty $\mathrm{a}_{\mathrm{m}} \mathrm{a} \mathrm{D}$. Jednotlivé soubory matečných hornin a půd (tj. vzorky z jedné lokality) jsou v tabulce 2 seřazeny podle rostoucí hodnoty poměru $\mathrm{D}_{\text {půda }} / \mathrm{D}_{\text {hornina }}$. Tabulka 3 shrnuje údaje o obsazích $\mathrm{K}, \mathrm{U}$, Th a $\mathrm{z}$ nich vypočtených hodnotách $a_{m}$ ve třech studovaných frakcích půd, které jsou v tabulce a následujícím textu označovány jako HP ( 0,5 až $2 \mathrm{~mm}$, tj. velmi hrubozrnný a hrubozrnný písek), JP (0,063 až $0,5 \mathrm{~mm}$, tj. středně zrnitý, jemnozrnný a velmi jemnozrnný písek) a $\mathrm{S}+\mathrm{J}$ (pod 0,063 mm, tj. částice zrnitostně odpovídající siltu a jílu).

Významné či zajímavé poznatky jsou komentovány v následujících odstavcích:

1. Hodnota poměru $\mathrm{D}_{\text {pủdal }}$ / $\mathrm{D}_{\text {hornina }}$ na 45 studovaných lokalitách se pohybuje v intervalu 0,38 až 21,45. Na 25 lokalitách (tj. 56\% lokalit) je přirozená radioaktivita půdy nižší než přirozená radioaktivita matečné horniny, lhostejno zda jako kritérium použijeme vypočtené hodnoty $\mathrm{D}$ nebo $\mathrm{a}_{\mathrm{m}}$.

2. Na horninách s relativně vysokými obsahy K (nad cca $1 \mathrm{hm}$. \%) se formují půdy, které obvykle mají nižší obsah draslíku než matečná hornina, jen někdy je v nich obsah draslíku mírně vyšší (hodnota poměru $\mathrm{K}_{\text {pủda }} / \mathrm{K}_{\text {hornina }}$ je do 1,2). Na horninách s nízkými obsahy K (pod cca 1 hm. \%) vznikají půdy, které mají vyšší obsah draslíku než matečná hornina, často velmi výrazně v rámci studovaného souboru hornin je to charakteristické pro pískovce, kvarcity, serpentinity a vápence. Zcela analogické chování bylo zaznamenáno i v př́padě uranu a thoria. Proto půdy vznikající na výše vyjmenovaných horninách vykazují výrazně vyšší přirozenou radioaktivitu ve srovnání přirozenou radioaktivitou matečných hornin (viz data $\mathrm{v}$ tab. 2).

3. $\mathrm{Z}$ dat $\mathrm{v}$ tabulce 2 by bylo možno usuzovat, že na horninách s poměrně vysokou přirozenou radioaktivitou (např. granitoidy a syenitoidy) se formují půdy, jejichž přirozená radioaktivita je sice relativně vysoká, avšak nižší než u matečných hornin (hodnota poměru $\mathrm{D}_{\text {půda }} / \mathrm{D}_{\text {hornina }}$ je 0,66 až 0,98$)$. Pro studovaný soubor sedmi granitoidů + syenitoidů a půd na nich vytvořených to bez výjimky platí, obecnou platnost však toto tvrzení nemá (viz např. Gong et al. 2013).

4. Data v tabulce 3 umožňují odpovědět na otázku, zda jsou v půdách přirozené radioaktivní prvky přednostně 
Tab. 2: Průměrné obsahy přirozených radioaktivních prvků (K, U, Th) v horninách (h) a půdách (p), vypočtené hodnoty hmotnostní aktivity ekvivalentu ${ }^{226} \mathrm{Ra}\left(\mathrm{a}_{\mathrm{m}}\right)$ a dávkového príkonu gama $(\mathrm{D})$.

Tab. 2: Average contents of natural radioactive element (K, $U, T h)$ in rocks (h) and soils (p), calculated values of mass activity of ${ }^{226} \mathrm{Ra}$ equivalent $\left(\mathrm{a}_{\mathrm{m}}\right)$ and gamma radiation dose rate $(\mathrm{D})$.

\begin{tabular}{|c|c|c|c|c|c|c|c|c|c|c|c|c|c|c|c|c|}
\hline \multirow{2}{*}{ lokalita } & \multirow{2}{*}{ hornina } & \multicolumn{3}{|c|}{$\mathrm{K}(\mathrm{hm} . \%)$} & \multicolumn{3}{|c|}{$\mathrm{U}(\mathrm{ppm})$} & \multicolumn{3}{|c|}{ Th (ppm) } & \multicolumn{3}{|c|}{$\mathrm{a}_{\mathrm{m}}\left(\mathrm{Bq} \cdot \mathrm{kg}^{-1}\right)$} & \multicolumn{3}{|c|}{$\mathrm{D}\left(\mathrm{nGy} \cdot \mathrm{h}^{-1}\right)$} \\
\hline & & $\mathrm{h}$ & $\mathrm{p}$ & $\mathrm{p} / \mathrm{h}$ & $\mathrm{h}$ & $\mathrm{p}$ & $\mathrm{p} / \mathrm{h}$ & $\mathrm{h}$ & $\mathrm{p}$ & $\mathrm{p} / \mathrm{h}$ & $\mathrm{h}$ & $\mathrm{p}$ & $\mathrm{p} / \mathrm{h}$ & $\mathrm{h}$ & $\mathrm{p}$ & $\mathrm{p} / \mathrm{h}$ \\
\hline VII & fylit & 3,0 & 0,8 & 0,26 & 2,1 & 1,1 & 0,52 & 7,6 & 4,0 & 0,53 & 144 & 56 & 0,39 & 73 & 28 & 0,38 \\
\hline XIV & světlý metatuf & 3,6 & 3,0 & 0,82 & 5,4 & 2,0 & 0,36 & 19,1 & 7,8 & 0,41 & 266 & 142 & 0,53 & 129 & 72 & 0,56 \\
\hline XVI & kvarcit & 0,2 & 1,0 & 5,56 & 2,4 & 0,8 & 0,31 & 13,7 & 4,4 & 0,32 & 114 & 59 & 0,52 & 52 & 29 & 0,56 \\
\hline XXI & granit & 3,4 & 2,5 & 0,72 & 3,9 & 2,4 & 0,63 & 17,4 & 10,6 & 0,61 & 232 & 151 & 0,65 & 113 & 74 & 0,66 \\
\hline XIX & metaprachovec & 1,7 & 1,1 & 0,66 & 1,6 & 1,5 & 0,90 & 6,9 & 4,6 & 0,67 & 100 & 71 & 0,71 & 49 & 35 & 0,71 \\
\hline XXXVI & migmatit & 1,4 & 0,7 & 0,53 & 0,6 & 0,4 & 0,73 & 7,2 & 6,6 & 0,92 & 82 & 61 & 0,74 & 41 & 30 & 0,73 \\
\hline XII & svor & 3,6 & 2,4 & 0,68 & 3,6 & 2,9 & 0,81 & 15,0 & 11,8 & 0,78 & 218 & 163 & 0,75 & 108 & 80 & 0,74 \\
\hline XXIX & křemenný syenit & 4,1 & 3,9 & 0,95 & 11,1 & 5,9 & 0,53 & 35,4 & 27,8 & 0,79 & 441 & 328 & 0,74 & 209 & 158 & 0,76 \\
\hline $\mathrm{XX}$ & granit & 3,1 & 3,0 & 0,96 & 3,3 & 2,0 & 0,58 & 11,7 & 7,7 & 0,66 & 184 & 141 & 0,77 & 91 & 71 & 0,78 \\
\hline $\mathrm{XXX}$ & křemenný syenit & 3,8 & 3,8 & 1,00 & 11,2 & 6,3 & 0,56 & 31,6 & 25,0 & 0,79 & 415 & 316 & 0,76 & 196 & 152 & 0,78 \\
\hline XXXIII & droba & 2,8 & 1,9 & 0,65 & 4,0 & 3,6 & 0,92 & 12,0 & 10,3 & 0,86 & 187 & 149 & 0,80 & 91 & 72 & 0,79 \\
\hline $\mathrm{XL}$ & diabas & 6,6 & 3,9 & 0,59 & 0,9 & 2,1 & 2,26 & 3,0 & 6,4 & 2,14 & 189 & 157 & 0,83 & 102 & 80 & 0,79 \\
\hline IX & svor & 2,5 & 1,6 & 0,66 & 2,0 & 1,8 & 0,92 & 10,6 & 11,1 & 1,05 & 146 & 126 & 0,87 & 72 & 61 & 0,85 \\
\hline I & ortorula & 2,6 & 1,8 & 0,69 & 0,9 & 1,7 & 1,94 & 7,0 & 6,4 & 0,91 & 113 & 101 & 0,89 & 58 & 50 & 0,87 \\
\hline XXXIX & droba & 1,7 & 1,8 & 1,03 & 2,3 & 2,0 & 0,87 & 11,0 & 8,2 & 0,74 & 134 & 116 & 0,86 & 65 & 57 & 0,87 \\
\hline VI & fylonit & 2,1 & 1,7 & 0,84 & 1,5 & 1,6 & 1,02 & 7,1 & 6,1 & 0,86 & 110 & 97 & 0,88 & 55 & 48 & 0,88 \\
\hline XXXIV & droba & 1,9 & 1,5 & 0,79 & 1,4 & 1,5 & 1,12 & 9,3 & 8,6 & 0,92 & 117 & 105 & 0,90 & 58 & 51 & 0,89 \\
\hline III & metaprachovec & 2,2 & 1,8 & 0,83 & 1,7 & 1,9 & 1,10 & 8,5 & 7,9 & 0,93 & 123 & 112 & 0,91 & 61 & 55 & 0,91 \\
\hline XXXII & křemenný syenit & 4,3 & 4,6 & 1,08 & 12,1 & 7,6 & 0,63 & 31,4 & 31,7 & 1,01 & 435 & 390 & 0,90 & 206 & 188 & 0,91 \\
\hline XXXI & křemenný syenit & 4,1 & 4,7 & 1,15 & 6,9 & 4,8 & 0,69 & 34,8 & 30,6 & 0,88 & 386 & 349 & 0,91 & 185 & 170 & 0,92 \\
\hline XVII & ortorula & 2,1 & 1,5 & 0,69 & 1,0 & 1,2 & 1,19 & 4,1 & 5,8 & 1,39 & 86 & 83 & 0,96 & 44 & 41 & 0,93 \\
\hline $\mathrm{X}$ & rula & 4,6 & 3,4 & 0,72 & 1,1 & 1,9 & 1,80 & 8,2 & 11,5 & 1,41 & 172 & 171 & 0,99 & 90 & 86 & 0,96 \\
\hline XXXV & droba & 1,9 & 2,0 & 1,06 & 2,7 & 2,4 & 0,88 & 11,1 & 10,1 & 0,91 & 144 & 136 & 0,95 & 70 & 67 & 0,96 \\
\hline XXXVIII & granit & 3,8 & 4,4 & 1,15 & 2,6 & 1,3 & 0,52 & 13,6 & 12,5 & 0,92 & 203 & 196 & 0,96 & 102 & 100 & 0,98 \\
\hline XXIII & droba & 1,9 & 1,7 & 0,92 & 2,5 & 2,7 & 1,06 & 9,4 & 9,8 & 1,04 & 132 & 132 & 1,00 & 64 & 64 & 0,99 \\
\hline II & ortorula & 2,6 & 2,3 & 0,87 & 0,9 & 1,7 & 1,89 & 5,7 & 7,0 & 1,23 & 108 & 117 & 1,09 & 55 & 59 & 1,06 \\
\hline XIII & metakeratofyr & 2,5 & 2,2 & 0,88 & 1,6 & 2,5 & 1,51 & 8,6 & 10,0 & 1,16 & 130 & 140 & 1,08 & 65 & 69 & 1,06 \\
\hline $\mathrm{XV}$ & bazický metatuf & 2,5 & 2,6 & 1,03 & 1,3 & 1,4 & 1,04 & 2,4 & 3,1 & 1,31 & 90 & 97 & 1,08 & 47 & 50 & 1,07 \\
\hline XXIV & paleobazalt & 4,9 & 4,5 & 0,92 & 3,6 & 4,8 & 1,34 & 3,6 & 5,6 & 1,55 & 184 & 201 & 1,09 & 95 & 101 & 1,07 \\
\hline XI & rula & 4,1 & 4,1 & 1,02 & 2,3 & 2,1 & 0,90 & 8,2 & 11,4 & 1,40 & 174 & 191 & 1,10 & 89 & 97 & 1,09 \\
\hline VIII & svor & 2,0 & 2,1 & 1,01 & 2,1 & 2,2 & 1,06 & 10,2 & 12,3 & 1,21 & 134 & 149 & 1,11 & 66 & 73 & 1,10 \\
\hline IV & metadroba & 1,3 & 1,2 & 0,95 & 2,1 & 2,3 & 1,11 & 4,9 & 6,4 & 1,31 & 85 & 95 & 1,12 & 42 & 46 & 1,11 \\
\hline XVIII & amfibolit & 1,3 & 1,3 & 0,94 & 1,0 & 2,3 & 2,35 & 1,8 & 2,5 & 1,42 & 54 & 73 & 1,34 & 28 & 36 & 1,28 \\
\hline XXVI & pískovec & 0,7 & 0,9 & 1,21 & 0,3 & 0,6 & 1,67 & 1,4 & 2,8 & 2,01 & 29 & 44 & 1,49 & 15 & 22 & 1,46 \\
\hline XXVII & pískovec & 0,6 & 1,0 & 1,54 & 0,5 & 1,2 & 2,30 & 2,4 & 3,5 & 1,46 & 36 & 58 & 1,64 & 18 & 29 & 1,62 \\
\hline V & amfibolit & 0,1 & 0,4 & 3,20 & 0,5 & 0,5 & 0,96 & 1,0 & 1,6 & 1,59 & 15 & 25 & 1,61 & 7 & 12 & 1,69 \\
\hline XLIV & serpentinit & $<0,1$ & $<0,1$ & & $<0,3$ & 0,4 & 1,54 & $<0,3$ & 1,1 & 5,00 & 6 & 13 & 2,21 & 3 & 6 & 2,09 \\
\hline XXII & kvarcit & 0,4 & 1,9 & 4,42 & 1,9 & 3,3 & 1,74 & 6,2 & 11,2 & 1,80 & 70 & 151 & 2,17 & 33 & 73 & 2,24 \\
\hline XXV & pískovec & 0,2 & 0,9 & 3,91 & 0,3 & 1,1 & 3,67 & 1,0 & 4,3 & 4,20 & 15 & 60 & 4,00 & 7 & 30 & 4,01 \\
\hline XXXVII & serpentinit & $<0,1$ & 0,3 & 4,43 & $<0,3$ & 0,5 & 2,65 & $<0,3$ & 2,1 & 10,35 & 5 & 26 & 4,97 & 2 & 13 & 5,04 \\
\hline XLII & vápenec & $<0,1$ & 1,0 & 14,86 & 1,0 & 3,0 & 3,11 & 0,3 & 11,7 & 38,87 & 15 & 130 & 8,51 & 7 & 61 & 9,00 \\
\hline XLV & serpentinit & $<0,1$ & 0,5 & 7,71 & $<0,3$ & 1,1 & 5,60 & $<0,3$ & 4,6 & 19,83 & 5 & 53 & 9,86 & 3 & 25 & 9,89 \\
\hline XLIII & vápenec & $<0,1$ & 0,9 & 12,57 & 0,4 & 2,7 & 6,00 & $<0,3$ & 10,3 & 44,60 & 9 & 114 & 13,38 & 4 & 54 & 13,76 \\
\hline XXVIII & vápenec & $<0,1$ & 1,3 & 19,85 & 0,5 & 2,7 & 5,83 & 0,3 & 11,2 & 41,33 & 9 & 131 & 14,52 & 4 & 62 & 15,15 \\
\hline XLI & vápenec & $<0,1$ & 1,1 & 15,71 & $<0,3$ & 2,6 & 12,90 & $<0,3$ & 9,9 & 43,20 & 5 & 116 & 21,46 & 3 & 55 & 21,45 \\
\hline
\end{tabular}

vázány na některou ze tř́ sledovaných zrnitostních frakcí. Taboada et al. 2006). Zcela obdobně půdy na pískovcích $\mathrm{V}$ př́ípadě půd, jejichž matečnou horninou jsou granitoidy a syenitoidy, je zcela zřejmé, že frakce $S+J$ má výrazně nižší obsahy K než frakce pískové a že obsahy U, Th a také hodnoty $\mathrm{a}_{\mathrm{m}}$ obecně rostou od HP přes JP po $\mathrm{S}+\mathrm{J}$. Toto zjištění je v souladu s některými již publikovanými údaji o distribuci přirozených radioaktivních prvkủ v granitoidech, jejich zvětralinách a půdách na nich vytvořených (např̀ a drobách vykazují relativně vysoké obsahy $\mathrm{U}$ a Th v $\mathrm{S}+\mathrm{J}$ ve srovnání s JP a HP.

5. Látkové složení půdy je různou měrou ovlivněno eolickým materiálem. Bylo by možno tvrdit, že relativně vysoké obsahy $\mathrm{K}, \mathrm{U}$ a Th $\mathrm{v}$ půdách na pískovcích, kvarcitech, serpentinitech a vápencích mohou zásadním způsobem souviset $s$ jeho depozicí. $V$ prrípadě půd na vá- 
Tab. 3: Obsahy přirozených radioaktivních prvků (K, U, Th) v zrnitostních frakcích půd, vypočtené hodnoty hmotnostní aktivity ekvivalentu ${ }^{226} \mathrm{Ra}\left(\mathrm{a}_{\mathrm{m}}\right)$.

Tab. 3: Natural radioactive element (K, U, Th) contents in grain size fractions of soils, calculated values of mass activity of ${ }^{226} \mathrm{Ra}$ equivalent $\left(\mathrm{a}_{\mathrm{m}}\right)$.

\begin{tabular}{|c|c|c|c|c|c|c|c|c|c|c|c|c|}
\hline \multirow{2}{*}{ lokalita } & \multicolumn{3}{|c|}{$\mathrm{K}(\mathrm{hm} . \%)$} & \multicolumn{3}{|c|}{$\mathrm{U}(\mathrm{ppm})$} & \multicolumn{3}{|c|}{ Th (ppm) } & \multicolumn{3}{|c|}{$\mathrm{a}_{\mathrm{m}}\left(\mathrm{Bq} \cdot \mathrm{kg}^{-1}\right)$} \\
\hline & HP & $J P$ & $\mathrm{~S}+\mathrm{J}$ & HP & JP & $\mathrm{S}+\mathrm{J}$ & $\mathrm{HP}$ & JP & $\mathrm{S}+\mathrm{J}$ & HP & $\mathrm{JP}$ & $\mathrm{S}+\mathrm{J}$ \\
\hline \multicolumn{13}{|c|}{ půdy na granitoidech a syenitoidech } \\
\hline $\mathrm{XX}$ & 4,1 & 2,8 & 1,8 & 0,8 & 2,4 & 5,3 & 3,0 & 9,9 & 20,5 & 126 & 155 & 228 \\
\hline XXI & 3,3 & 2,5 & 1,6 & 0,9 & 2,7 & 4,3 & 3,7 & 18,4 & 15,0 & 112 & 200 & 179 \\
\hline XXXVIII & 4,0 & 4,2 & 2,6 & 0,9 & 2,4 & 7,1 & 6,3 & 16,2 & 79,4 & 144 & 225 & 611 \\
\hline XXIX & 4,8 & 3,9 & 2,7 & 3,5 & 7,6 & 13,7 & 15,2 & 35,4 & 79,2 & 247 & 393 & 694 \\
\hline $\mathrm{XXX}$ & 3,4 & 3,9 & 3,1 & 3,7 & 15,1 & 12,7 & 14,9 & 45,1 & 42,7 & 214 & 542 & 479 \\
\hline XXXI & 5,7 & 5,8 & 3,2 & 1,8 & 4,8 & 11,9 & 11,1 & 30,4 & 76,4 & 224 & 376 & 668 \\
\hline XXXII & 4,8 & 3,7 & 4,0 & 4,3 & 14,1 & 32,7 & 13,7 & 48,7 & 112,8 & 248 & 546 & 1155 \\
\hline \multicolumn{13}{|c|}{ půdy na vulkanitech a metavulkanitech } \\
\hline XIII & 2,4 & 2,3 & 2,4 & 1,9 & 3,2 & 4,2 & 7,9 & 15,8 & 13,1 & 127 & 187 & 186 \\
\hline XIV & 4,4 & 3,3 & 3,6 & 2,0 & 2,6 & 2,8 & 9,2 & 8,9 & 8,7 & 184 & 163 & 172 \\
\hline XV & 3,3 & 2,5 & 2,9 & 1,2 & 2,0 & 1,3 & 3,3 & 3,5 & 7,1 & 114 & 105 & 127 \\
\hline XVIII & 1,6 & 1,4 & 1,3 & 2,6 & 2,4 & 3,3 & 2,9 & 2,4 & 4,5 & 88 & 77 & 98 \\
\hline $\mathrm{V}$ & 0,6 & 0,3 & 0,9 & 0,5 & 1,2 & 0,4 & 2,1 & 2,5 & 3,2 & 33 & 37 & 45 \\
\hline XXIV & 5,9 & 4,2 & 3,1 & 5,5 & 5,7 & 4,9 & 4,9 & 8,6 & 8,5 & 239 & 222 & 185 \\
\hline $\mathrm{XL}$ & 4,8 & 2,8 & 2,9 & 2,2 & 2,0 & 3,2 & 7,3 & 8,3 & 8,9 & 185 & 140 & 161 \\
\hline \multicolumn{13}{|c|}{ půdy na vápencích (XXVIII a XLI), piskovcích (XXV a XXVII) a drobách (XXXIII a XXXV) } \\
\hline XXVIII & 1,6 & 1,5 & 1,7 & 3,3 & 3,1 & 4,5 & 13,6 & 15,0 & 13,0 & 158 & 162 & 172 \\
\hline XLI & 1,7 & 1,3 & 1,2 & 5,4 & 3,6 & 3,6 & 13,8 & 12,4 & 16,0 & 188 & 148 & 166 \\
\hline XXV & 0,8 & 0,5 & 1,9 & 1,6 & 0,9 & 2,7 & 4,6 & 2,1 & 9,1 & 66 & 35 & 132 \\
\hline XXVII & 1,3 & 0,8 & 1,7 & 2,2 & 0,9 & 2,6 & 5,2 & 2,0 & 11,7 & 89 & 42 & 141 \\
\hline XXXIII & 2,0 & 2,0 & 1,8 & 3,3 & 3,6 & 4,7 & 9,9 & 8,5 & 12,5 & 146 & 142 & 174 \\
\hline XXXV & 2,0 & 1,7 & 1,9 & 1,9 & 2,8 & 2,8 & 9,7 & 11,6 & 14,3 & 128 & 143 & 163 \\
\hline
\end{tabular}

pencích (tab. 3) lze významnější vliv eolického materiálu (ve frakcích S+J a JP) vyloučit, nebot rozdíly v obsazích přirozených radioaktivních prvků ve frakcích $\mathrm{HP}, \mathrm{JP}$ a S+J jsou poměrně malé.

6. Koncentrace přirozených radioaktivních prvků v půdním profilu je vždy výsledkem jejich migrace a re- distribuce $\mathrm{v}$ hypergenním prostředí. $\mathrm{V}$ další etapě výzkumu bude provedeno sledování distribuce $\mathrm{K}, \mathrm{U}$ a Th ve vybraných pedogenetických profilech.

\section{Závěr}

Na základě stanovení obsahů přirozených radioaktivních prvků (K, U a Th) v 514 vzorcích půd a matečných hornin ze 45 lokalit ve východní části Českého masivu lze konstatovat, že v literatuře uváděná tvrzení typu „půdy a zvětralé vrstvy mají obsahy $\mathrm{K}$, U, Th menší než nerozrušená podložní hornina“ nemají obecnou platnost. Na více než polovině studovaných lokalit (56\%) je přirozená radioaktivita půdy skutečně o něco nižší než přirozená radioaktivita matečné horniny, a to zpravidla díky nižším obsahům všech tří sledovaných prvků v půdě. To je typické např́klad pro půdy na granitoidech a syenitoidech, ale lze se s tímto jevem setkat i u pưd vyvinutých na jiných typech hornin $s$ relativně vysokou přirozenou radioaktivitou. Z hlediska interpretace dat získaných leteckou gamaspektrometrií nebo gamaspektrometrickým měřením na terénu s půdním pokryvem má zásadní význam zjištění, že půdy vytvořené na horninách s nízkými obsahy K, U a Th, jako jsou např́iklad křemenné pískovce, serpentinity a vápence, mají vyšší obsahy těchto prvků (a často i řádově vyšší) ve srovnání s matečnými horninami.

\section{Literatura}

Gong, Q. - Deng, J. - Wang, Ch. - Wang, Z. - Zhou, L. (2013): Element behaviors due to rock weathering and its implication to geochemical anomaly recognition: A case study on Linglong biotite granite in Jiaodong peninsula, China. - Journal of Geochemical Exploration 128, 14-24.

Matolín, M. - Chlupáčová, M. (1997): Radioaktivní vlastnosti hornin. - In: Kobr, M. et al.: Petrofyzika, 109-126. Vydavatelství Karolinum, Praha.

Ngachin, M. - Garavaglia, M. - Giovani, C. - Kwato Njock, M. G. - Nourreddine, A. (2007): Assessment of natural radioactivity and associated radiation hazards in some Cameroonian building materials. - Radiation Measurements, 42, 61-67.

Taboada, T. - Cortizas, A. M. - García, C. - García-Rodeja, E. (2006): Uranium and thorium in weathering and pedogenetic profiles developed on granitic rocks from NW Spain. - Science of the Total Environment, 356, 192-206.

UNSCEAR, United Nations Scientific Committee on the Effects of Atomic Radiation (1988): Exposures from natural sources of radiation. Report to the General Assembly. - U. N., New York, USA. 